\title{
ESTIMASI PARAMETER MODEL PROBIT PADA DATA PANEL MENGGUNAKAN OPTIMASI BFGS
}

\author{
Parameter Estimation of Probit Model on Panel Data Using BFGS \\ Optimization
}

\author{
Halistin $^{1 *}$, Vita Ratnasari ${ }^{2}$, Santi Puteri Rahayu ${ }^{3}$, Tandri Patih ${ }^{4}$ \\ 1,2,3,4 Tadris Matematika, Fakultas Tarbiyah dan Ilmu Keguruan, IAIN Kendari \\ Jl. Sultan Qaimuddin No. 17 Baruga, Kota Kendari, 93117 \\ e-mail: 1* halistinsulaeman@gmail.com ; ${ }^{2}$ vitaratna70@gmail.com ; \\ ${ }^{3}$ sprahayu@gmail.com; ${ }^{4}$ tandripatih@gmail.com \\ Corresponding author*
}

\begin{abstract}
Abstrak
Penelitian ini bertujuan untuk melakukan kajian analitik estimasi parameter regresi probit pada data panel menggunakan Maximum Likelihood Estimation (MLE) dengan teknik optimasi Broyden-FletcherGoldfarb-Shanno (BFGS). Regresi probit adalah salah satu model yang dapat menjelaskan pola hubungan antara variabel dependen yang bersifat kategorik dengan variabel independen. Jika pemodelan regresi probit melibatkan data silang dan deret waktu, disebut model probit data panel. Estimasi parameter model probit data panel random effect ini menggunakan maximum likelihood estimation (MLE) dengan pendekatan Gauss Hermite Quadrature. Proses iterasi menggunakan metode BFGS. Metode BFGS ini digunakan untuk mendapatkan hasil estimasi parameter yang closed form.
\end{abstract}

Kata Kunci :Probit, Data Panel, Gauss Hermite Quadrature, BFGS.

Abstract

One model that may explain the pattern of the relationship between the categorical dependent variable and the independent variables is probit regression. In the probit regression, the independent variable can be categorical or continuous. Probit regression is using the link function of the standard normal distribution. If the probit regression modeling involves a cross-section data and time series data, it is called probit data panel model. Parameter estimation of random effect probit data panel model is using the maximum likelihood estimation (MLE) method with Gauss Hermite Quadrature approach. Iterative procedure by using BFGS method. BFGS method used to obtain the close form value of the parameter estimates.

Keywords: Probit, Panel Data, Gauss Hermite Quadrature, BFGS. 


\section{PENDAHULUAN}

Regresi probit merupakan metode statistik yang digunakan untuk mengetahui hubungan antara variabel respon dan prediktor, dengan variabel respon yang digunakan berskala kategori dan fungsi linknya mengikuti distribusi normal standar [1]. Regresi probit dapat digunakan untuk membentuk model probabilitas linier apabila variabel responnya merupakan variabel kategori [2]. Istilah "probit" dalam regresi probit merupakan singkatan dari "probability unit", istilah ini dikenalkan pertama kali oleh Bliss [3] melalui penelitiannya mengenai pestisida dengan variabel respon terdiri atas 2 kategori. Beberapa penelitian telah mengkaji penggunaan regresi probit pada berbagai kasus dengan variabel respon berupa data kategorik, seperti dilakukan oleh Astsaqofi [4], Dwitiyanti [5], Nurseto,dkk [6], Tinungki [7], Sari, dkk [8], Puspita, dkk [9], Wulandari dan Trisutanto [10], Utami [11], Andriani, dkk [12], Malldina, dkk [13], Agustina [14], Rahmadeni dan Yunita [15], dan Pradnyantari, dkk [16]. Akan tetapi, penelitian-penelitian sebelumnya lebih banyak menguraikan pengembangan model probit secara empiris pada berbagai studi kasus. Kajian model probit secara analitik belum banyak dilakukan, khususnya regresi probit pada data panel. Sehingga, penelitian ini bertujuan untuk melakukan kajian analitik estimasi parameter regresi probit pada data panel menggunakan Maximum Likelihood Estimation (MLE) dengan teknik optimasi Broyden-Fletcher-Goldfarb-Shanno (BFGS). Hasil penelitian ini dapat menjadi bahan referensi bagi peneliti selanjutnya dalam mengembangkan kajian analitik terkait regresi probit secara umum dan regresi probit pada data panel secara khusus. Pemodelan regresi probit dapat diawali dengan memperhatikan model sebagai berikut [17].

$$
Y=\boldsymbol{\beta}^{\mathbf{T}} \mathbf{x}+\varepsilon
$$

Menurut Greene [17] Variabel respon kualitatif $Y$ berasal dari variabel respon yang tidak teramati $\ddot{Y}^{*}$ yaitu $Y^{*}=\boldsymbol{\beta}^{T} \mathbf{x}+\varepsilon$. Dimana variabel $\mathbf{x}$ adalah variabel prediktor, yang dinotasikan $\mathbf{x}=\left[\begin{array}{llll}1 & X_{1} & \cdots & X_{p}\end{array}\right]^{T}$ dengan ukuran $(p+1) \times 1$, dan $q$ adalah banyaknya variabel prediktor. Paramteter $\boldsymbol{\beta}$ adalah vektor parameter koefisien, $\quad \boldsymbol{\beta}=\left[\begin{array}{lllll}\beta_{\mathbf{0}} & \beta_{\mathbf{1}} & \cdots & \beta_{q}\end{array}\right]^{T}$ yang berukuran $(p+1) \times 1$. Variabel $\varepsilon$ diasumsikan berdistribusi Normal dengan mean 0 dan varians 1 . PDF dari variabel $Y^{*}$ adalah $f\left(y^{*}\right)=\frac{1}{\sqrt{2 \pi}} \exp \left(-\frac{1}{2}\left(y^{*}-\boldsymbol{\beta}^{T} \mathbf{x}\right)^{2}\right) . Y^{*}$ berdistribusi Normal dengan mean $\boldsymbol{\beta}^{T} \mathbf{x}$ dan varians satu.

Pembentukan kategori pada variabel respon $Y$ dilakukan dengan memberikan nilai thresshold tertentu, misalkan $\gamma$. Pada model probit biner dengan 1 nilai thresshold yaitu $\gamma$. Untuk $Y^{*} \leq \gamma$ dikategorikan dengan $Y=0$.Sedangkan untuk $Y^{*}>\gamma$ dikategorikan dengan $Y=1$. Model probit biner dapat ditulis dengan $p(\mathbf{x})=1-\Phi\left(\gamma-\boldsymbol{\beta}^{\mathbf{T}} \mathbf{x}\right)$ dimana $\Phi\left(\gamma-\boldsymbol{\beta}^{\mathbf{T}} \mathbf{x}\right)=\Phi($.$) merupakan fungsi distribusi kumulatif normal standar.$

Regresi probit data panel merupakan model regresi probit dengan struktur data panel. Regresi probit merupakan salah satu model nonlinear. Dalam model nonlinear, random effect lebih banyak dikembangkan daripada fixed effect. Maddala [18] menjelaskan bahwa model probit random effect lebih popular digunakan dibandingkan dengan model probit lainnya. Model probit random effect memberikan estimasi yang konsisten dan dapat mengakomodasi heterogenitas. Sedangkan model probit fixed effect memberikan estimasi yang tidak konsisten untuk $\boldsymbol{\beta}$ dan jika terdapat korelasi antara efek individu terhadap variabel independen maka estimator yang diperoleh menjadi tidak efisien. Dalam paper ini akan dilakukan estimasi parameter model probit data panel random effect.

Model probit data panel random effect dapat ditulisan sebagai berikut.

$$
\begin{aligned}
& y_{i t}^{*}=\mathbf{x}_{i t}{ }^{\mathrm{T}} \boldsymbol{\beta}+\varepsilon_{i t} \quad i=1,2, \ldots, n \\
& t=1,2, \ldots, T \\
& \varepsilon_{i t}=u_{i}+v_{i t} \\
& y_{i t}= \begin{cases}1 & \text { jika } y_{i t}^{*}>\gamma \\
0 & j i k a y_{i t}^{*} \leq \gamma\end{cases}
\end{aligned}
$$

dengan 


$$
P\left(y_{i t}=0 \mid \mathbf{x}_{i t}, u_{i}, \boldsymbol{\beta}\right)=\Phi\left(\mathbf{x}_{i t}{ }^{T} \boldsymbol{\beta}+u_{i}\right)
$$

Dimana $y_{i t}$ adalah pengamatan untuk data ke- $i$ pada waktu ke- $t, \mathbf{x}_{i t}$ adalah vektor berukuran $1 \times(p+1)$ pada variabel prediktor, $\boldsymbol{\beta}$ adalah vektor berukuran $(p+1) \times 1$ untuk koefisien parameter, $u_{i}$ adalah random efek individu yang tidak teramati dan $v_{i t}$ adalah random error. $u_{i}$ dan $v_{i t}$ merupakan variabel random independen dengan,

$\mathrm{E}\left[u_{i} \mid \mathrm{X}\right]=0 ; \operatorname{Cov}\left[u_{i}, u_{j} \mid \mathrm{X}\right]=\operatorname{Var}\left[u_{i} \mid \mathrm{X}\right]=\sigma_{u}^{2} \quad$ jika $i=j ; 0$ untuk lainnya

$\mathrm{E}\left[v_{i t} \mid \mathrm{X}\right]=0 ; \operatorname{Cov}\left[v_{i t}, v_{j s} \mid \mathrm{X}\right]=\operatorname{Var}\left[v_{i t} \mid \mathrm{X}\right]=1$ jika $i=j$ dan $t=s ; 0$ untuk lainnya

$\operatorname{Cov}\left[v_{i t}, u_{j} \mid \mathrm{X}\right]=0$, untuk semua $i, j, t$ dan $\mathbf{X}$ merupakan data variabel prediktor $\mathbf{x}_{i t}$ untuk semua $i$ dan $t$. Kemudian korelasi antara $i$ adalah konstan, dengan,

$$
E\left[\varepsilon_{i t} \mid \mathrm{X}\right]=0, \operatorname{Var}\left[\varepsilon_{i t} \mid \mathrm{X}\right]=\sigma_{v}^{2}+\sigma_{u}^{2}=1+\sigma_{u}^{2}, \operatorname{Corr}\left[\varepsilon_{i t}, \varepsilon_{i s} \mid \mathrm{X}\right]=\rho=\frac{\sigma_{u}^{2}}{1+\sigma_{u}^{2}}
$$

Sehingga diperoleh parameter bebas yang baru yaitu $\sigma_{u}^{2}=\frac{\rho}{(1-\rho)}, \rho$ adalah korelasi antar error pada individu yang sama [17].

Metode estimasi parameter yang digunakan untuk pemodelan pada regresi probit data panel random effect adalah Maximum Likelihood Estimation (MLE). [19] telah melakukan penelitian dengan membandingkan beberapa metode estimasi probit biner data panel random effect dan menemukan bahwa MLE lebih efisien dan konsisiten. Dalam estimasi parameter probit data panel menggunakan MLE sulit untuk diselesaikan secara analitik, sehingga digunakan pendekatan metode Gauss Hermite Quadrature sebagaimana yang diusulkan [20]. Gauss-Hermite menggantikan integrasi dengan jumlah bobot pada fungsi yang diitung pada serangkaian titik tertentu. Secara umum dapat dituliskan seperti persamaan (4).

$$
\frac{1}{\sqrt{\pi}} \int_{-\infty}^{\infty} g\left(w_{i}\right) \exp \left(-w_{i}\right) d w_{i} \approx \frac{1}{\sqrt{\pi}} \sum_{m=1}^{M} w_{m}^{*} g\left(a_{m}^{*}\right)
$$

Dimana $w_{m}^{*}$ adalah bobot quadrature dan $a_{m}^{*}$ adalah titik node/absis dari quadrature. Karena hasil estimasi parameter tidak closed form, harus dilanjutkan dengan menggunakan metode optimasi Broyden-FletcherGoldfarb-Shanno (BFGS) dengan pertimbangan bahwa iterasi pada metode ini lebih cepat mencapai konvergensi dibandingkan metode lain [21].

\section{METODE PENELITIAN}

Metode estimasi parameter yang digunakan adalah Maximum Likelihood Estimation (MLE) dengan langkah-langkah sebagai berikut.

a) Mengasumsikan $y$ biner dengan pemodelan probit data panel (2)

b) Ambil $n$ sampel random $y_{1 t}, y_{2 t}, \ldots, y_{n t}$

c) Menentukan fungsi likelihood dari variabel random $y_{1 t}, y_{2 t}, \ldots, y_{n t}$ yaitu

d) Menyelesaikan fungsi likelihood dengan Gauss Hermite Quadrature (4)

e) Memaksimumkan fungsi likelihood dengan menurunkan ln fungsi likelihood terhadap parameter dan kemudian menyamakan dengan nol.

$$
\frac{\partial \ln L}{\partial(\boldsymbol{\beta}, \rho)}=\mathbf{0}
$$

f) Jika diperoleh bentuk yang tidak closed form, maka untuk memperoleh penaksir maksimum likelihood digunakan penyelesaian dengan menggunakan metode numerik dengan iterasi BFGS.

Prosedur iterasi dari metode ini adalah sebagai berikut [9]: 
1) Diberikan $l=0, \boldsymbol{\beta}^{0}$ adalah nilai awal. Pilih sembarang matriks definit positif $\mathbf{H}^{(0)}$ (sering digunakan $\left.\mathbf{H}^{(0)}=\mathbf{I}\right)$

2) Pada langkah $l$, hitung arah perpindahan $\mathbf{d}^{l}=-\mathbf{H}^{l} \nabla j\left(\boldsymbol{\beta}^{l}\right)$ dan mendapatkan $\boldsymbol{\beta}^{l+1}$ dari minimum $j\left(\boldsymbol{\beta}^{l}+\alpha \mathbf{d}^{l}\right)$ dimana $\alpha \geq 0$

3) Hitung $\boldsymbol{\delta}^{l}=\boldsymbol{\beta}^{l+1}-\boldsymbol{\beta}^{l}$ dan $\boldsymbol{\gamma}^{l}=\nabla j\left(\boldsymbol{\beta}^{l+1}\right)-\nabla j\left(\boldsymbol{\beta}^{l}\right)$ untuk menghitung matriks pembaruan BFGS:

$$
\mathbf{H}^{l+1}=\mathbf{H}^{l}+\left[1+\frac{\left(\boldsymbol{\gamma}^{l}\right)^{T} \mathbf{H}^{l}\left(\boldsymbol{\gamma}^{l}\right)}{\left(\boldsymbol{\delta}^{l}\right)^{T} \boldsymbol{\gamma}^{l}}\right] \frac{\boldsymbol{\delta}^{l}\left(\boldsymbol{\delta}^{l}\right)^{T}}{\left(\boldsymbol{\delta}^{l}\right)^{T} \boldsymbol{\gamma}^{l}}-\frac{\boldsymbol{\delta}^{l}\left(\boldsymbol{\gamma}^{l}\right)^{T} \mathbf{H}^{l}+\mathbf{H}^{l} \boldsymbol{\gamma}^{l}\left(\boldsymbol{\delta}^{l}\right)^{T}}{\left(\boldsymbol{\delta}^{l}\right)^{T} \boldsymbol{\gamma}^{l}}
$$

4) Iterasi berhenti ketika $\left\|\boldsymbol{\beta}^{l+1}-\boldsymbol{\beta}^{l}\right\|<\varepsilon$. Dengan $\varepsilon$ adalah bilangan yang sangat kecil.

\section{HASIL DAN PEMBAHASAN}

Model probit pada data panel dapat dituliskan sebagai berikut.

$$
P\left(y_{i t}=0 \mid \mathbf{x}_{i t}, u_{i}, \boldsymbol{\beta}\right)=\Phi\left(\mathbf{x}_{i t} \boldsymbol{\beta}+u_{i}\right)^{y_{i t}}
$$

dengan $\Phi($.$) merupakan fungsi distribusi kumulatif normal standar. Densitas bersama dari T$ pengamatan $y_{i t}$ dengan $u_{i}$ diasumsikan independen pada individu yang sama adalah

$$
P\left(y_{i 1}, y_{i 2}, \ldots, y_{i T} \mid \mathbf{X}_{i}, u_{i}\right)=\prod_{t=1}^{T} f\left(y_{i t} \mid \mathbf{x}_{i t}, u_{i}, \boldsymbol{\beta}\right)=\prod_{t=1}^{T} \Phi\left(\mathbf{x}_{i t} \boldsymbol{\beta}+u_{i}\right)^{y_{i t}}\left[1-\Phi\left(\mathbf{x}_{i t} \boldsymbol{\beta}+u_{i}\right)^{1-y_{i t}}\right](6)
$$

$u_{i}$ adalah bagian dari pengamatan dan diasumsikan berdistribusi normal, untuk mengkonstruksikan loglikelihood, maka [4]

$$
L_{i}=\int_{-\infty}^{\infty}\left[\prod_{t=1}^{T} f\left(y_{i t} \mid \mathbf{x}_{i t}, u_{i}, \boldsymbol{\beta}\right)\right] \frac{1}{\sqrt{2 \pi \sigma_{u}^{2}}} \exp \left(-\frac{u_{i}^{2}}{2 \sigma_{u}^{2}}\right) d u_{i}
$$

Misalkan $w_{i}=\frac{u_{i}}{\sigma_{u} \sqrt{2}}$ maka $u_{i}=\left(\sigma_{u} \sqrt{2}\right) w_{i}=\theta w_{i}$. Selanjutnya mengubah variabel dalam integral, seperti pada persamaan (8).

$$
\begin{aligned}
L_{i} \quad & =\int_{-\infty}^{\infty}\left[\prod_{t=1}^{T} f\left(y_{i t} \mid \mathbf{x}_{i t}, \theta \mathrm{w}_{i}, \boldsymbol{\beta}\right)\right] \frac{1}{\theta \sqrt{\pi}} \exp \left(-w_{i}^{2}\right) \theta d w_{i} \\
& =\frac{1}{\sqrt{\pi}} \int_{-\infty}^{\infty}\left[\prod_{t=1}^{T} f\left(y_{i t} \mid \mathbf{x}_{i t}, \theta \mathrm{w}_{i}, \boldsymbol{\beta}\right)\right] \exp \left(-w_{i}^{2}\right) d w_{i}
\end{aligned}
$$

Pada umumnya secara analitik sulit untuk menyelesaikan (8). [21] mengusulkan menggunakan pendekatan Gauss-Hermite Quadrature. Gauss-Hermite menggantikan integrasi dengan jumlah bobot pada fungsi yang diitung pada serangkaian titik tertentu (4).

Jika $g\left(w_{i}\right)=\prod_{t=1}^{T} f\left(y_{i t} \mid \mathbf{x}_{i t}, \theta w_{i}, \boldsymbol{\beta}\right)$, dengan menggunakan (4), maka fungsi likelihood:

$$
\begin{aligned}
L \quad & =\prod_{i=1}^{N} L_{i} \\
& =\prod_{i=1}^{N} \frac{1}{\sqrt{\pi}} \sum_{m=1}^{M} w_{m}^{*}\left[\prod_{t=1}^{T} f\left(y_{i t} \mid \mathbf{x}_{i t},\left(\sigma_{u} \sqrt{2}\right) a_{m}^{*}, \boldsymbol{\beta}\right)\right]
\end{aligned}
$$

Diketahui bahwa $\sigma_{u}=\left(\frac{\rho}{1-\rho}\right)^{1 / 2}$, sehingga fungsi likelihood pada Persamaan (9) dapat diubah menjadi (10) berikut. 


$$
L(\boldsymbol{\beta}, \rho)=\prod_{i=1}^{N} \frac{1}{\sqrt{\pi}} \sum_{m=1}^{M} w_{m}^{*}\left[\prod_{t=1}^{T}\left(\Phi\left(\mathbf{x}_{i t}{ }^{T} \boldsymbol{\beta}+a_{m}^{*}\left(\frac{2 \rho}{1-\rho}\right)^{1 / 2}\right)\right)^{y_{i t}}\left(1-\Phi\left(\mathbf{x}_{i t}{ }^{T} \boldsymbol{\beta}+a_{m}^{*}\left(\frac{2 \rho}{1-\rho}\right)^{1 / 2}\right)\right)^{1-y_{i t}} \mathrm{j}\right]
$$

Fungsi likelihood yang terbentuk pada Persamaan (10) selanjutnya dimaksimumkan dengan terlebih dahulu dinyatakan dalam bentuk fungsi ln-likelihood.

$$
\begin{aligned}
\ln L & =\sum_{i=1}^{n} \ln \left\{\frac{1}{\sqrt{\pi}} \sum_{m=1}^{M} w_{m}^{*}\left[\prod_{t=1}^{T}\left(\Phi\left(\mathbf{x}_{i t}^{T} \boldsymbol{\beta}+a_{m}^{*}\left(\frac{2 \rho}{1-\rho}\right)^{1 / 2}\right)\right)^{y_{i t}}\left(1-\Phi\left(\mathbf{x}_{i t}^{T} \boldsymbol{\beta}+a_{m}^{*}\left(\frac{2 \rho}{1-\rho}\right)^{1 / 2}\right)\right)^{1-y_{i t}}\right]\right\} \\
& =n \ln \frac{1}{\sqrt{\pi}}+\sum_{i=1}^{n} \sum_{t=1}^{T} \sum_{m=1}^{M} w_{m}^{*}\left(\Phi\left(\mathbf{x}_{i t}^{T} \boldsymbol{\beta}+a_{m}^{*}\left(\frac{2 \rho}{1-\rho}\right)^{1 / 2}\right)\right)^{y_{i t}}+\sum_{i=1}^{n} \sum_{t=1}^{T} \sum_{m=1}^{M} w_{m}^{*}\left(1-\Phi\left(\mathbf{x}_{i t}^{T} \boldsymbol{\beta}+a_{m}^{*}\left(\frac{2 \rho}{1-\rho}\right)^{1 / 2}\right)\right)^{1-y_{i t}}
\end{aligned}
$$

Langkah selanjutnya melakukan turunan pertama terhadap $\boldsymbol{\beta}$ dan $\rho$ sebagai berikut:

Turunan terhadap $\beta_{0}$ :

$$
\begin{gathered}
\frac{\partial \ln L}{\partial \beta_{0}}=\sum_{i=1}^{n} \sum_{t=1}^{T} \sum_{m=1}^{M} w_{m}^{*} y_{i t}\left(\Phi\left(\mathbf{x}_{i t}^{T} \boldsymbol{\beta}+a_{m}^{*}\left(\frac{2 \rho}{\rho-1}\right)^{1 / 2}\right)\right)^{y_{i n}-1} \phi\left(\mathbf{x}_{i t}^{T} \boldsymbol{\beta}+a_{m}^{*}\left(\frac{2 \rho}{\rho-1}\right)^{1 / 2}\right) \\
+\sum_{i=1}^{n} \sum_{t=1}^{T} \sum_{m=1}^{M} w_{m}^{*}\left(1-y_{i t}\right)\left(1-\Phi\left(\mathbf{x}_{i t}^{T} \boldsymbol{\beta}+a_{m}^{*}\left(\frac{2 \rho}{\rho-1}\right)^{1 / 2}\right)\right)^{-y_{i n}}\left(-\phi\left(\mathbf{x}_{i t}^{T} \boldsymbol{\beta}+a_{m}^{*}\left(\frac{2 \rho}{\rho-1}\right)^{1 / 2}\right)\right) \\
\vdots
\end{gathered}
$$

Turunan terhadap $\beta_{p}$ :

$$
\begin{aligned}
\frac{\partial \ln L}{\partial \beta_{p}} & =\sum_{i=1}^{n} \sum_{t=1}^{T} \sum_{m=1}^{M} w_{m}^{*} y_{i t}\left(\Phi\left(\mathbf{x}_{i t}^{T} \boldsymbol{\beta}+a_{m}^{*}\left(\frac{2 \rho}{\rho-1}\right)^{1 / 2}\right)\right)^{y_{i t}-1}\left(\phi\left(\mathbf{x}_{i t}^{T} \boldsymbol{\beta}+a_{m}^{*}\left(\frac{2 \rho}{\rho-1}\right)^{1 / 2}\right)\right)\left(x_{i t p}\right) \\
& +\sum_{i=1}^{n} \sum_{t=1}^{T} \sum_{m=1}^{M} w_{m}^{*}\left(1-y_{i t}\right)\left(1-\Phi\left(\mathbf{x}_{i t}^{T} \boldsymbol{\beta}+a_{m}^{*}\left(\frac{2 \rho}{\rho-1}\right)^{1 / 2}\right)\right)^{-y_{i t}}\left(-\phi\left(\mathbf{x}_{i t}^{T} \boldsymbol{\beta}+a_{m}^{*}\left(\frac{2 \rho}{\rho-1}\right)^{1 / 2}\right)\right)\left(x_{i t p}\right)
\end{aligned}
$$

Turunan terhadap $\rho$ :

$$
\begin{aligned}
\frac{\partial \ln L}{\partial \rho}= & \sum_{i=1}^{n} \sum_{t=1}^{T} \sum_{m=1}^{M} w_{m}^{*} y_{i t}\left(\phi\left(\mathbf{x}_{i t}^{T} \boldsymbol{\beta}+a_{m}^{*}\left(\frac{2 \rho}{\rho-1}\right)^{1 / 2}\right)\right)^{y_{i t}-1}\left(\phi a_{m}^{*}\left(\frac{(1-\rho)^{-3 / 2}}{(2 \rho)^{1 / 2}}\right)\right) \\
& -\sum_{i=1}^{n} \sum_{t=1}^{T} \sum_{m=1}^{M} w_{m}^{*}\left(1-y_{i t}\right)\left(1-\phi\left(\mathbf{x}_{i t}^{T} \boldsymbol{\beta}+a_{m}^{*}\left(\frac{2 \rho}{\rho-1}\right)^{1 / 2}\right)\right)^{-y_{i t}}\left(\phi a_{m}^{*}\left(\frac{(1-\rho)^{-3 / 2}}{(2 \rho)^{1 / 2}}\right)\right)
\end{aligned}
$$

Berdasarkan turunan pertama, misalkan:

$$
\nabla j(\boldsymbol{\beta}, \rho)=\left[\frac{\partial \ln L}{\partial \beta_{0}}, \frac{\partial \ln L}{\partial \beta_{1}}, \frac{\partial \ln L}{\partial \beta_{2}}, \ldots, \frac{\partial \ln L}{\partial \rho}\right]^{T}
$$

Jika $\nabla j(\boldsymbol{\beta}, \rho)=0$ maka diperoleh estimasi yang tidak closed form sehingga diperlukan metode iterasi. Metode iterasi yang digunakan adalah BFGS. Algoritma BFGS adalah sebagai berikut.

a. Diberikan $l=0, \boldsymbol{\beta}^{0}$ adalah nilai awal. Pilih sembarang matriks definit positif $\mathbf{H}^{(0)}$ (sering digunakan $\left.\mathbf{H}^{(0)}=\mathbf{I}\right)$

$$
\mathbf{H}=\left[\begin{array}{cccc}
1 & 0 & \ldots & 0 \\
0 & 1 & \ldots & 0 \\
0 & 0 & \ldots & 0 \\
0 & 0 & \ldots & 1
\end{array}\right]_{(p+1) \times(p+1)}
$$


b. Pada langkah $l$, hitung arah perpindahan $\mathbf{d}^{l}=-\mathbf{H}^{l} \nabla j\left(\boldsymbol{\beta}^{l}\right)$

$$
\mathbf{d}^{l}=-\mathbf{H}\left[\begin{array}{cccc}
1 & 0 & \ldots & 0 \\
0 & 1 & \ldots & 0 \\
0 & 0 & \ldots & 0 \\
0 & 0 & \ldots & 1
\end{array}\right]_{(p+1) \times(p+1)}\left[\begin{array}{c}
\frac{\partial \ln L}{\partial \beta_{0}} \\
\frac{\partial \ln L}{\partial \beta_{1}} \\
\vdots \\
\frac{\partial \ln L}{\partial \beta_{p}}
\end{array}\right]_{(p+1) \times 1}
$$

dan mendapatkan $\boldsymbol{\beta}^{l+1}$ dari minimum $j\left(\boldsymbol{\beta}^{l}+\alpha \mathbf{d}^{l}\right)$ dimana $\alpha \geq 0$

c. Hitung $\boldsymbol{\delta}^{l}=\boldsymbol{\beta}^{l+1}-\boldsymbol{\beta}^{l}$ dan $\boldsymbol{\gamma}^{l}=\nabla j\left(\boldsymbol{\beta}^{l+1}\right)-\nabla j\left(\boldsymbol{\beta}^{l}\right)$ untuk menghitung matriks pembaruan BFGS:

$$
\mathbf{H}^{l+1}=\mathbf{H}^{l}+\left[1+\frac{\left(\boldsymbol{\gamma}^{l}\right)^{T} \mathbf{H}^{l}\left(\boldsymbol{\gamma}^{l}\right)}{\left(\boldsymbol{\delta}^{l}\right)^{T} \boldsymbol{\gamma}^{l}}\right] \frac{\boldsymbol{\delta}^{l}\left(\boldsymbol{\delta}^{l}\right)^{T}}{\left(\boldsymbol{\delta}^{l}\right)^{T} \boldsymbol{\gamma}^{l}}-\frac{\boldsymbol{\delta}^{l}\left(\boldsymbol{\gamma}^{l}\right)^{T} \mathbf{H}^{l}+\mathbf{H}^{l} \boldsymbol{\gamma}^{l}\left(\boldsymbol{\delta}^{l}\right)^{T}}{\left(\boldsymbol{\delta}^{l}\right)^{T} \boldsymbol{\gamma}^{l}}
$$

d. Iterasi berhenti ketika $\left\|\boldsymbol{\beta}^{l+1}-\boldsymbol{\beta}^{l}\right\|<\varepsilon$. Dengan $\varepsilon$ adalah bilangan yang sangat kecil.

\section{KESIMPULAN}

Estimasi parameter model probit data panel random effect menggunakan metode maximum likelihood estimation (MLE) diperoleh dengan pendekatan Gauss Hermite Quadrature. Pendekatan ini, terbukti mampu menyederhanakan proses analitik pada MLE. Nilai estimasi parameter yang closed form diperoleh setelah menggunakan metode BFGS.

\section{DAFTAR PUSTAKA}

[1] A. Agresti, Categorical Data Analysis, Second. Gainesville, Florida: John Wiley \& Sons, Inc, 2002.

[2] J. Aldrich and F. Nelson, Linear probability logit and probit models, vol. 8, no. 6. Lowa: Sara Miller McCune, Sage Publications, Inc., 1987.

[3] C. I. Bliss, "The Method of Probits," Science (80-. )., vol. 79, no. 2037, pp. 38-39, 1934, doi: 10.1126/science.79.2037.38.

[4] M. Astsaqofi, "Analisis Regresi Probit dengan Efek Interaksi untuk Memodelkan Indeks Pembangunan Manusia di Indonesia," Institut Teknologi Sepuluh Nopember, 2016.

[5] N. Dwitiyanti, "Model regresi probit bivariat," Fakt. Exacta, vol. 10, no. 3, pp. 210-216, 2017, doi: https://dx.doi.org/10.30998/faktorexacta.v10i3.1336.

[6] T. Nurseto, B. Suprayitno, and Mustofa, "Penggunaan Model Probit Untuk Melakukan Peramalan Pencapaian Hasil Belajar Mata Kuliah Kuantitatif," Pros. Semin. Nas. ..., pp. 597-613, 2015.

[7] G. M. Tinungki, "Aplikasi Model Regresi Logit dan Probit pada Data Kategorik," J. Mat. Stat. Komputasi, vol. 6, no. 2, pp. 107-114, 2010.

[8] B. Sari and F. Widjajati, "Model Regresi Probit Bivariat pada Kasus Penderita HIV dan AIDS di Jawa Timur," J. Sains dan Seni ITS, vol. 4, no. 2, pp. A61-A66, 2015.

[9] F. I. Puspita, V. Ratnasari, and P. Purhadi, "Model Probit Spasial pada Faktor-Faktor yang Mempengaruhi Klasifikasi IPM di Pulau Jawa," Cauchy, vol. 2, no. 4, p. 198, 2013, doi: 10.18860/ca.v2i4.3116.

[10] E. Wulandari and H. Trisutanto, "Model regresi probit untuk mengetahui faktor-faktor yang mempengaruhi jumlah penderita diare di Jawa Timur," MATHunesa, vol. 2, no. 1, pp. 1-6, 2010.

[11] R. R. Utami, "Analisis Regresi Probit Biner pada Faktor-Faktor yang Mempengaruhi Kemiskinan Rumah Tangga di Kecamatan Pujut Kabupaten Lombok Tengah,” Universitas Mataram, 2018.

[12] D. Andriani, S. Wahyuningsih, and Y. N. Nasution, "Pemodelan Regresi Probit Ordinal Pada Kasus Penentuan Predikat Kelulusan Mahasiswa FMIPA Universitas Mulawarman Tahun 2014,” Pros. Semin. Sains dan Teknol. FMIPA Unmul, pp. 513-520, 2016. 
[13] T. Malldina, B. Tantular, D. Y. Faidah, and G. Darmawan, “Analisis Regresi Probit Untuk Menentukan Peluang Kemenangan Pemain Dalam Permainan Age of Empire 2,” Pros. Semin. Nas. MIPA 2016, pp. 17-20, 2016.

[14] A. Agustina, "Pemodelan Faktor Risiko yang Berhubungan dengan Tingkat Keparahan Pelaku Kecelakaan Lalu Lintas di Kabupaten Tuban Jawa Timur dengan Regresi Logistik Ordinal,” J. Ilm. Kesehat. Media Husada, vol. 05, no. 2, pp. 119-127, 2016.

[15] Rahmadeni and V. Yunita, "Pemodelan Indeks Pembangunan Manusia di Provinsi Riau dengan Menggunakan Regresi Logistik Ordinal," J. Sains Mat. dan Stat., vol. 5, no. 1, pp. 120-126, 2019.

[16] N. G. K. T. PRADNYANTARI, I. K. G. SUKARSA, and N. L. P. SUCIPTAWATI, "Penerapan Regresi Probit Bivariat untuk Menduga Faktor-Faktor yang Memengaruhi Kelulusan Mahasiswa (Studi Kasus: Mahasiswa Fakultas MIPA Unversitas Udayana)," E-Jurnal Mat., vol. 4, no. 2, pp. 49-53, 2015, doi: 10.24843/mtk.2015.v04.i02.p088.

[17] W. Greene, Análisis econométrico, 7th ed. New York: Pearson, 2008.

[18] G. S. Maddala, "Limited Dependent Variable Models Using Panel Data," J. Hum. Resour., vol. 22, no. 3, pp. 307-338, 1987, doi: 10.2307/145742.

[19] M. N. Harris, L. R. Macquarie, and A. J. Siouclis, “A Comparison of Alternative Estimators for Binary Panel Probit Models," Melb. Inst. Work. Pap., vol. No. 3/00, no. June, pp. 0-20, 2000.

[20] J. S. Butler and R. Moffitt, "A Computationally Efficient Quadrature Procedure for the One-Factor Multinomial Probit Model," Econometrica, vol. 50, no. 6, p. 1596, 1982, doi: 10.2307/1913405.

[21] E. Chong and S. Zak, An Introduction to Optimization, Second Edi. New York: John Wiley \& Sons, Inc, 2001. 
